Nataša Šofranac

\title{
SEĆANJE NA ŠEKSPIRA I SEĆANJE KOD ŠEKSPIRA
}

Sećanje se čini prigodnom temom za zbornik priređen u čast naših nezaboravnih profesora. Sećanje kao mentalna, ali i emocionalna i moralna, čak i fiziološka kategorija, dotiče se celog niza drugih tema i oblasti: individualnog i kolektivnog pamćenja, traume, identiteta, tradicije i transformacije. Ovaj rad u prvom delu bavi se sećanjem na Šekspira i njegov život posle smrti, a u drugom sećanjem na primeru junaka iz tragedija Hamlet i Magbet.

Ključne reči: Šekspir, sećanje, tumačenje, Hamlet, Magbet.

\section{SVI ŽIVOTI SISTEMSKI VILIJEMA ŠEKSPIRA}

Sećanje je nestalna i manipulisanju podložna osobina, osetljiva na subjektivnost i skrivene motive. Takvo je i sećanje kod Šekspira, ali i sećanje na Šekspira. Ono što Šekspir hoće da kaže, ili ono što mi hoćemo da kažemo Šekspirom, kako se izrazio Teri Hoks (2002: 2), menja se u zavisnosti od okolnosti i svrhe. Ugnjetenima je, recimo, Šekspir bio inspiracija i nada u oslobođenje, dok je za pristalice poretka i hijerarhije on kamen međaš na putu sopstvenog održanja. Džulijet Dusinber (Juliet Dusinberre) tvrdi da se Šespirov značaj u smislu pobune mnogo jasnije razaznaje po uticaju koji njegove drame imaju na neslobodno društvo, kakvo je bilo njegovo i kakvo je današnje mnogo manje (2003: xxix). Recimo, u nekadašnjim komunističkim zemljama, ili u Južnoj Africi pod aparthejdom. Ako se vratimo još dalje 
u prošlost, videćemo Čartistički pokret Tomasa Kupera i narastajući nacionalni ponos toga doba, ili romantičarski pokret njegovih savremenika u vreme Habsburške monarhije na koji je podsetio profesor Juan Ferni prilikom gostovanja u Beogradu 2016. godine1. Mnogi su u tamnicama čitali Šekspirova dela i iz njegovog duha crpeli snove o slobodi. Ili, ako uzmemo demagogiju i manipulaciju u Juliju Cezaru, koja pokazuje stalnost ljudske nestalnosti kroz milenijume, publika se i danas lako pronalazi u pitanjima: "Who is here so base that would be a bondman? Who is here so rude that would not be a Roman? Who is here so vile that will not love his country? (Julius Caesar, III.ii).

Rim je dobar primer onoga što Ričard Bart naziva diskurzivnim determinizmom - kako se istorija starog Rima može preslikati na renesansu i kako sada čitamo Julija Cezara tumačeći ga kroz prizmu današnjice (LoGAN-Rudnytsky 1991: 112). Zapravo, postoje tri momenta koja treba imati u vidu: vreme o kome Šekspir piše, vreme u koje je Šekspir pisao i vreme u koje mi to čitamo. Kako Bart kaže, „upisati prošlost ne znači i prepisati budućnost”.

„Da li je Šekspir i dalje naš savremenik?”, pitali su šekspirolozi prilikom obeležavanja 25. godišnjice čuvene knjige Jana Kota, kako je to zabeležio Džon Elsom. Sada nam više ni Jan Kot nije savremenik. On je verovao da je Šekspir uvek naš savremenik, na ovaj ili onaj način, ali u nekim vremenima on nam je više savremenik nego u nekim drugim. Profesor Kot objašnjava šta znači reč „savremenik”: „To je neka vrsta odnosa između dva vremena, jednog na pozornici i drugog van nje" (ELsom: 1989: 11-12). Bertolt Breht, koga Kot često citira, insistira na tome da Šekspir nije vanvremenski već čovek svog vremena i da je njegova univerzalnost u opisima jedne faze ljudskog razvitka (ELSom: 1989: 4). Preispituju se čak i stari postulati i aksiomi, uvode nezamislive promene u zauvek dati poredak, poput pojave nove zvezde supernove koja se pominje na početku drame Hamlet (OLson: 1998). Nikada nećemo znati koliko je Šekspir bio svestan revolucionarnih ideja

1 Tokom 2016. godine Britanski savet organizovao je seriju predavanja, manifestacija i konkursa pod nazivom "Shakespeare Lives". U okviru nje, profesor Ferni održao je predavanje u beogradskom Centru „Sava”. 
kojima odišu njegova dela, kako ih mi čitamo, uranjajući ih u more svog znanja, iskustva i prezentizma. Ali jedno je sigurno - Šekspir je pogodio žicu „setnog ljudskog poja” ("the still sad music of humanity”), kako je rekao njegov obožavalac Vordsvort (Kuić 1986: 144-5) i „držao ogledalo pred prirodom" ("held the mirror up to Nature"), po rečima dr Samujela Džonsona u predgovoru Šekspirovim sabranim delima iz 1765. godine (JumP 1968: 23).

Pre više od stotinu godina, u jeku Prvog svetskog rata, na londonskoj konferenciji u čast 300-te godišnjice Śekspirove smrti, Srbiju su predstavljali teolog Nikolaj Velimirović, čije je saopštenje „Šekspir svečovek", objavljeno u spomen knjizi ovog događaja, i profesor Pavle Popović. Otac Nikolaj je Šekspirovu popularnost u slovenskom svetu objasnio njegovim panhumanizmom, koji krišom gravitira prema njegovom istočnom pandanu Dostojevskom. U njegovom čarobnom jeziku, kaže otac Nikolaj, Sloveni su pronašli najjasniji izraz svoje duše i on ... „pravi razliku između dobra i zla 'plastično', kao Biblija” (Milanović 1995). I nastavlja: "I do not know Shakespeare. Even I cannot know him. But he knows me; he described me, he painted all the secrets of my soul..." (90). Čini se da, ceo vek kasnije, mislimo isto i još uvek tragamo za mnogim odgovorima, ali Šekspir ih nije nudio; on je postavljao pitanja i opisivao, a ne prepisivao.

Za moderne kritičare obezličenost je sine qua non: nije bitna ličnost Vilijema Šekspira, možda on nikada i nije postojao, već je bio prototip modernog umetnika koji poseduje genijalnost srazmernu sposobnosti rastakanja njegove ličnosti. Henri Džejms u njegovim dramama nije video čoveka, „već samo čarobnjaka i čudovište sa hiljadu maski" (TAYLOR 2001: 83). Džojsovog Stivena Dedalusa fascinira kontroverza autorstva. U jednom trenutku on pominje Šekspira kao „Rutlandbaconsouthamptonshakespeare-a ili drugog pesnika koji se isto zvao", parafrazirajući doskočicu o Homeru kao pesniku istog imena koji je pisao njegove epove (GARBER 2008: 215). Nakon što su postmodernisti osporili koncept lika, a poststrukturalisti proglasili smrt autora, da li uopšte ima smisla istraživati lične stavove autora ili analizirati njegove likove kao tipove? (WAYNE 1991: 262) Šekspirovi 
junaci prerasli su u ličnosti za sebe, živeći mnoge živote. Uzmimo na primer Hamleta - „dražesnog mizantropa”, kako ga je nazvao romantičar Hazlit (Jump 1968: 15̃), prolongatora ili nežnog princa koga su romantičari idealizovali. Jedna od najnovijih vivisekcija takvih junaka sa mnogo lica je i knjiga Macbeth, Macbeth Juana Fernija i Sajmona Palfrija, koji su istoimenog junaka podelili na sve ostale muške likove u drami. Uz sveprisutno pitanje očinstva, tu je i novootkriveno pitanje majčinstva, koje je ranije odbacivano kao nebitno - setimo se britke rasprave koju je sa zagovornicima tog pitanja vodio Majkl Bristol pod naslovom „Koliko li je imala dece?” "How Many Children Did She Have?" (Joughin 2003: 16). Lokalne priče oko zamka Invernes, kako su ih rekonstruisali Ferni i Palfri, čuvale su sećanje na Magbeta kao na sina Doade, žene napravljene od mleka. Ali, mlečni čovek se zgrušao nakon kobnog susreta sa vešticama i zanosa usled njihovog proročanstva. Njegova hrabra žena koja mu je stalno pružala podršku imala je tri dojke koje je ugljem bojila u crno svake noći da bi rasterala siročad, kako su šapatom prenosili seljani. Nakon zločina, pretvorila je svoj zamak u utočište za mlade žene, ali nije želela da ikada ponovo vidi neku majku. Kada bi se neka devojka porodila, bebe bi se rešili, a mladu majku oterali. Ali, to nije bilo dobro za dušu, tako da je jednog dana upala u najdublje jezero Škotske (FerniE-PALFRY 2016). Od mnogih Šekspirovih transformacija i života posle smrti, Magbet Ežena Joneska² nudi istu priču o ambiciji i državnom udaru, smeštenu u moderno vreme i teatar apsurda. Da li je to i dalje Šekspir ili Joneskovo svetogrđe, kako su ga doživeli neki razočarani ljubitelji Šekspira?

Ili, da se osvrnemo na izvedbe Hamleta: 1979. godine, Melisa Mari režirala je komad sa naslovom Ofelija za englesku pozorišnu trupu „Hormonski poremećaj”, gde Ofelija postaje lezbijka i odbegne sa jednom sluškinjom u gerilsku komunu, u potrazi za slobodom i sopstvom (BRooKer-Widdowson 2013: 39). Godine 1991, Aldo Nikolaj (Aldo Nicolai) režirao je dramu Hamletu pikantnom sosu (Hamlet in Spicy Sauce), kombinujući apokrifni stil, „crnu” komediju i pastiš, dok je Hamletov svet smešten u kuhinju Elsinora; haos u državi nastaje od haosa u ku-

2 Predstava na repertoaru pozoriša „Atelje 212”. 
hinji. Hamlet razvija homoseksualnu sklonost prema Laertu, Ofelija je u incestuoznoj vezi sa Laertom, a Horacio dobija maniju Don Žuana (Jovanov 2003); sve do Hamleta iz jubilarne, 2016. godine, u produkciji Kraljevskog Šekspirovog pozorišta (RSC), gde putujući glumci izvode jamajčanski ples i hip-hop, a glavni junak ima mnogo više energije i humora u odnosu na kontemplativnog nordijskog princa.

Profesor Ričard Vilson insistira da je Šekspir suviše dragocen za britansko društvo da bi bio ostavljen u škrinji „kao porodično srebro". Kao umetnički predmet, spomenik starim bogovima, Šekspirova drama mora se iznova tumačiti, izmeštati, preuzimati. U radovima reditelja poput Dejvida Takera ili Majkla Bogdanova, Šekspir se još može pokazati kao „trojanski konj koji će uzdrmati kulturnu tvrđavu” (TAYLOR 2001: 185). Postoji još takvih podsticaja da se Šekspir radikalizuje, da se društvo menja uticajem na šire stanovništvo, ali još više u metaforičnom smislu. I tu pozornica može mnogo više nego čitanje ili kritika. Alan Sinfild u knjizi Politički Šekspir (Political Shakespeare) pesimistično je doživeo Šekspira kao reprodukciju postojećeg poretka (LOGAN-RudNYTSKY 1991: 125): „kako god da se drame predstave, one će uvek biti relativno konzervativna priča ... a da bi jedna takva kulturna pojava imala toliki autoritet, mora sputavati radikalne inovacije". Grinblat, Goldberg i Tenenhaus tvrdili su da su Šekspirovi komadi i pozorište kao institucija funkcionisali kao konzervativna ideološka praksa koja je služila interesima političke ortodoksije, dok su pripadnici kulturnog materijalizma poput Drakakisa, Dolimora i Sinfilda odbijali da pozorište vide kao instrument države (LoGAN-RUDNYTSKY 1991: 109). Majkl Bristol je 1996. godine napisao da je Šekspir bio „moralno neprincipijelni oportunista, proračunate strategije i vođen diktatom tržišta”. (Logan-RUdnyTSKY 1991: 77). Pronicljiv verovatno jeste bio, ali setimo se njegovog soneta broj 66 u kome se žali kako mu je „vlast sputala jezik" ili drama u kojima se služi bezbednom tehnikom opisivanja mana kod engleskog naroda pripisivanjem tih mana drugim nacijama (Danskoj u Hamletu, Rimu u Juliju Cezaru i Koriolanu ili Grčkoj u Troilu $i$ Kresidi), ili pak komentara koje njegovi neengleski likovi izriču na račun Engleza (njihove navike da preteruju u piću u Otelu ili sirovi udvarač lepe Porcije u Mletačkom trgovcu). Njegov „,̌kotski 
komad” napisan je u čast novog kralja, elementima čije Demonologije je Šekspir protkao ovu dramu o unutrašnjim i spoljnim, zamišljenim i pravim demonima.

Eho reči profesora Vilsona čuo se u govoru Majkla Bogdanova u diskusiji sa Janom Kotom i ostalima, o Šekspiru kao našem savremeniku: „Za mene glavna uloga pozorišta nije samo da prosvetli i postane hronika svog vremena. [kako Hamlet opisuje ulogu glumaca.] Ona je i u pomaganju procesa promene" (TAYLOR 2001: 17). Danas je, s obzirom na ulogu mas medija, manje verovatno da pozorište može da ima toliki uticaj. Zbog toga više nema zabranjenih predstava, jer njihov domašaj je srazmerno mali.

Dvosmisleno je, kao i mnogo šta kod Šekspira, da li je bio protofeminista ili mizogin, s obzirom na glasove mržnje prema ženama u njegovim dramama, da li je bio antisemita, s obzirom na govor mržnje protiv Jevreja, ili rasista, s obzirom na rasizam u Otelu, Titu Androniku, da li je bio katolik ili protestant, subverzivan ili lojalan? Toliko je elemenata i delića svih njegovih kulturnih susreta. Ali, njegovi egalitaristički govori poput onoga o muškarcima i ženama (Emilija u Otelu, III.iv.100), hrišćanima i Jevrejima (Šajlok u Metačkom trgovcu) ili Perditin san u Zimskoj bajci, u kome sunce jednako obasjava i dvor i kolibu siromašnih pastira, najbolje su jemstvo Šekspirovog panhumanizma. Džulijet Dusinber veruje da su za Šekspira muškarci i žene bili jednaki, u svetu koji ih je proglasio nejednakim. Odbijao je da njihove svetove razdvoji fizički, duhovno i intelektualno (2003: 308). Od kraja osamdesetih godina nastupa dinamičan razvoj feminističke kritike, koja uzima u obzir drugačije analitičke pristupe poput marksizma, psihoanalize, antropologije i materijalizma, što „podstiče heterogenost” (TAYLoR 2001: 196), na način kako su to radile Ketrin Belzi ili Liza Džardin. Džulijet Dusinber odaje Šekspiru priznanje za to što je odbijao da ženama dodeli tradicionalno inferiorne uloge, čime je zaslužio naziv feministe avant la lettre (TAYLOR 2001: 197).

Vrpca u bojama duge koju je istakao čuveni glumac Dejvid Garik povodom prve proslave Šekspirovog jubileja, 1769. godine, neodoljivo podseća na današnji LGBT pokret i poziv na inkluzivno i tolerantno 
društvo. ${ }^{3}$ Ljubav između Mavra i bele Mlečanke bila je iznenadno izvrtanje norme, kaže Rut Kauvig (TAYLOR 2001: 210). Od 1933. godine, nacistički glumac Verner Kraus glumio je sve Jevreje, predstavljajući ih kao komične i zle. Ser Lorens Olivije je u pozno viktorijansko doba igrao Šajloka u cilindru i fraku, dizraelijevskog Šajloka, rotšildovskog Sajloka. Kada je Amerika počela da traži isplatu ratnog duga nakon Prvog svetskog rata, pojavio se nadimak „Ujka Šajlok”. Pored Romea, Šajlok je jedini Šekspirov lik koji je ušao u rečnike kao imenica za sebe. Za Karla Marksa Šajlok je bio alegorijski glas Kapitala, a Majkl Bogdanov je rekao da bi Hamlet bio savršen votergejtski komad u kome svi lepe „bubice” ispod stola (GARBER 2006). Kada je izbio Foklandski rat, 1982. godine, knjiga Authors Fake Sides on the Folklands (Autori zauzimaju strane po pitanju Foklandskih ostrva, 1983) beleži reči podrške čuvenog šekspirologa Džordža Vilsona Najta ulozi britanske krune kao „preteče ili prototipa svetskog poretka”. On je podsetio na reči iz Šekspirove poslednje drame, Henri VIII, da bi potkrepio takav stav o demokratiji, ,ali demokratija je stroga potčinjenost kruni kao simbolu koji povezuje ljubav sa vlašću i društveni poredak sa božanskim” (BARKER i dr. 1986: 183-85).

\section{0 SEĆANJU U ŠEKSPIROVIM DRAMAMA: HAMLET I MAGBET}

Skepticizam ranog modernog doba preispitivao je pouzdanost pamćenja i egzemplarnosti, dok je zaborav bio politički čin (HoLBRooK 2006: 119)4. Individualna memorija teško da može razvejati sumnje. Naprotiv, ona rasplamsava sumnje u verodostojnost sećanja, za razliku od egzemplarnosti i kolektivnog sećanja. Otuda potreba za nepo-

3 Profesor Ferni u pomenutom gostovanju u Beogradu podsetio je na festival Šekspiru u čast koji je organizovao čuveni glumac Dejvid Garik.

4 Videti Anita Gilman Sherman, "The Aesthetic Strategies of Skepticism: Mixing Memory and Desire in Shakespeare”, 99-119 u Peter Holbrook (ed.) The Shakespeare International Yearbook, Special Section 6: Shakespeare and Montaigne Revisited, Ashgate, 2006. 
verenjem u sud i percepciju. Za razliku od Montenja, koji svoju nepouzdanu memoriju pravda čisto fiziološkim razlozima, kod Šekspira to ima politički ili neki drugi skriveni motiv - postoje tri tipa: likovi na sceni koji se prisećaju odsutnih; odsutni (mrtvi) likovi koji se pojavljuju kako u tim sećanjima, tako i neposredno na sceni, obično u obliku duha; a ima i likova, obično majki, koje se čak i ne pominju, ali čije je odsustvo čak i teže nego prisustvo jer guše muške likove (kao u Kralju Liru). Recimo, Otelova majka i dalje živi kroz čuvenu marami$\mathrm{cu}$ - participation mystique, kako je Levi-Bril objasnio postuteralnu vezu između majke i deteta i detetovu nesposobnost da dovrši ciklus emocionalnog sazrevanja (SAvić 2002: 99). Odsutne majke zahtevaju kitsovsku „negativnu sposobnost” da se zamisli kakve su bile, a nikada se ne pominju pred decom. Sećanje na majku briše se u Liru, za razliku od prvobitnog zapleta gde drama počinje njenom smrću.

Novija paradigma u tumačenju Hamleta, kako je primetio Benet Sajmon (2001: 710), zasniva se na Hamletu i traumi. Važna knjiga na koju podseća Sajmon je Shattered Assumptions autorke Roni JanofBulman, iz 1992. godine. Trauma razbija pretpostavke o najbližem i najdražem kome možemo verovati, te ostajemo bez tla pod nogama kroz zemljotres unutarporodične izdaje. Tumačenje događaja postaje ograničeno ili haotično, ili i jedno i drugo. Utrnulost (kao kod Magbeta kada primi vest o smrti supruge) oscilira u labilnosti i nepotpunoj kontroli nad emocijama. Jedan od najkrupnijih uticaja traume je teškoća u zaključivanju da li je to što se događa stvarno. Trauma kida veze između „logičnih odnosa” i „ljudskih odnosa”. Preziremo sopstveno ja, kao i ceo svet, dok nastupa duboko nepoverenje u budućnost. U naporima da savladamo traumu, najčešći vidovi ponašanja su misija osvete i uloga žrtvenog jarca. U Hamletu, žrtveni jarci su pre svega žene, kao i sam Hamlet. Primetan je „posttraumatski stresni poremećaj” (eng. PTSD). Ali, za Hamleta bi više odgovarao termin „složeni traumatski stresni poremećaj”, kako ga je definisao Herman 1992. godine. To znači da traumatični događaji nisu sasvim ostavljeni u prošlosti. Priča koja se ne može ispričati neposrednim narativom nalazi izraz u izmeštanju, simbolizaciji i činjenju, kako je objasnio Frojd u eseju „Sećanje, ponavljanje i prerađivanje” (eng. "Remembering, 
Repeating and Working Through"), 1914. godine (STRAnChEY 1964). Neka sećanja je nemoguće izraziti rečima, pa se izražavaju neverbalno, kao telesna iskustva. Zbog toga Ledi Magbet piše pisma i pečati ih, tu je ono neizrecivo što je mogla odati samo svom uzglavlju u dubokom snu. „Disocijacija” pre nego „represija” odgovara opisu različitih načina na koje znanje postaje konfuzno i otudeno usled traumatičnog stanja (Šofranac 2011: 47-48).

Hamlet je ozbiljno traumatizovan sećanjima Duha, koja ga ostavljaju u neizvesnosti, ali i sigurnosti u to da mu je oca ubio stric, kao i to da je majka bila u dosluhu sa ubicom, ili barem da je izdala uspomenu na skoro preminulog muža. Nakon što je čuo traumatično iskustvo Duha o bratoubistvu, Hamlet doživljava indukciju od tog traumatičnog sećanja, koje je njegova „proročka duša” već nosila, a Duh samo hermeneutički pokrenuo. Tako Hamleta ne traumatizuje samo otkriće koje mu saopšti Duh, nego i sam „transfer” sećanja sa Duha na Hamleta (vidi Šofranac 2011: 48). Postoji li indukcija sećanjima? Ili, suprotno tome, može li se sećanje nekome iščupati iz glave, kako Magbet zahteva od lekara svoje žene, ili odstraniti kao što je slučaj sa sećanjem na Kordeliju nakon njenog odlaska u Francusku? Prisutna u razmeni doskočica između Lude i Edgara, kada Luda kaže "Her boat hath a leak, / And she must not speak; / Why she dares not come over to thee!" (III.vi.26-29), Kordelija je predmet očeve čežnje i mora da zaboravi na sebe da bi ga spasla. Ona ima ulogu majke iz Hamleta, gde sin želi celu njenu pažnju i čija je snaga istvoremeno plaši. Tek kad se odvoji od muža, kao i sestara, koje oličavaju žensku seksualnost, Kordelija može da se ponovo sjedini sa ocem i omogući mu iskupljenje. Heteroseksualna ljubav i brak su nemogući u Šekspirovim tragedijama i seku se u korenu: Romeo i Julija, Antonije i Kleopatra, Otelo, Troil $i$ Kresida.

Hamlet je bio melanholičan i pre susreta sa Duhom, ali sada odlučuje da se pretvara da je lud. Za razliku od njega, koga Duh mora da podseća na dato obećanje, Ofelija se uvek pridržava očevih naredbi i ispunjava ih. Montenj u svom eseju „O lažovima” (HAzLITT: 1877) kaže da jako sećanje često znači slabo rasuđivanje, ali i to da „manje pamtim uvrede; trebalo bi da vodim dnevnik uvreda ili da imam šaptača, 
kao Darije, koji je, da ne bi zaboravio uvrede Atinjana, držao uza sebe šaptača koji bi mu kad sedne za večeru tri puta ponovio „Gospodaru, seti se Atinjana”; Duh je bio Hamletov šaptač. Njegovo sećanje na oca je idealizovano; a metateatarski kraj ove drame koji nam govori o tome šta se zbilo kao da želi da nam usadi gotovo sećanje na način kako ga vidi govornik.

Ofelijinu traumu još više otežava tajnost i nemogućnost da govori o tome šta se desilo. Ona Hamleta pamti kao "the courtier's, soldier's, scholar's, eye, tongue, sword; The expectancy and rose of the fair state, / The glass of fashion and the mould of form, The observed of all observers” [i da sećanje boli, videvši] „such a noble mind overthrown”. Možda ne može da se otme tom utisku i zbog toga nije traumatizovana Hamletovim ponižavajućim postupanjem, budući da je više traumatizuje to što vidi da se dešava drugima (Hamletovo ludilo, očeva smrt) nego to što se dešava njoj. Hamletova trauma kod njega treba da izazove delanje, a njena je samo čini nemoćnom da preživi. U „manastirskoj sceni” Ofelija kaže Hamletu da su kod nje neke uspomene koje želi da mu vrati. Da li se sećanje može nekome vratiti? Da li može neko drugi da nam „da” sećanje i da mu ga vratimo kada ga više ne želimo? (vidi: Šofranac 2011: 48-49).

Trauma takođe poremeti osećaj stvarnosti, pa dovodi do poricanja ili prekida veza. U sećanjima Ledi Magbet na materinstvo, recimo, koji deo je stvaran? I Hamlet i duh njegovog oca prebacuju Klaudiju (i Gertrudi) „rodoskrvnuće” i „preljubu”. Brak između brata i žene preminulog kralja nije se smatrao rodoskrvnim, posebno ako je trebalo sačuvati imovinu i krunu (vidi Šofranac 2011: 49). Ostali likovi u drami nikada ne pominju ,incest”, tako da je pitanje da li se Hamlet fiksira na temu zbog Edipovog kompleksa, sećanja na ljubav između majke i pokojnog oca, na koju je bio ljubomoran, a na koju ga podseća novi brak sa Klaudijem? Teorija traume naglašava i indirektno pripovedanje o onome što se ne zna ili ne sme ispričati. Hamletu je za ubistvo rekao Duh. On ne zna da li je Gertruda bila saučesnik, kao što mi ne znamo da li Hamlet glumi ludilo ili da li je brak između Gertrude i Klaudija zaista bio incestuozan. Hamlet ne može javno da ispriča šta je čuo od Duha, pa iz Ofelijinog izveštaja o njegovom upadu u njenu 
sobu saznajemo kako je izgledao i kako se ponašao (2.1. 81-83). Ofelija ne može da izrekne koliko je potresena, besna i potiskivana, pa peva o smrti svog oca i o ljubavi sa Hamletom. Hamlet igrokazom „Mišolovka” prikazuje ono što nije mogao da ispriča. Na kraju, rečima „ispričati” i „izvestiti” (5.3. 312-18) pokušava da povrati prekinuti narativ, tipičan za traumu (vidi Šofranac 2011: 49).

Duh od Hamleta želi da osveti ubijenog oca, ali na rastanku mu ponavlja reči: „Pamti me!” (1.5. 95-104). Kako je Grinblat rekao, u celoj drami dešava se „skretanje sa osvete na sećanje” (2001: 206). Hamleta na samoubilačke misli navodi sećanje na oca: "So excellent a King! .../...Heaven and Earth, / Must I remember? (1.2.139-3).. Platon i Aristotel sećanje objašnjavaju po funkcijama pretraživanja i čuvanja, ali ne i neželjenog opsedanja. Hamlet kaže "I shall not look upon his like again" (1.2.186), što je na granici između sećanja i proganjanja. Proglasi da će samo naređenje Duha živeti u njegovom sećanju, a da će sve drugo izbrisati. Kako se radnja nastavlja, Sekspir meša sećanje sa zaboravom (vidi Šofranac 2011: 49). Kada frenetično insistira na tome da Gertruda primeti Duha, on kao da se plaši da će njemu izbledeti iz sećanja: "Look how he steals away" (3.4.125). Profesor Veselin Kostić to primećuje u semantičkoj analizi prevoda reči kojima razumni Horacio naziva Duha, kada ga, još na početku, smatra priviđenjem ili aveti: “Stay, illusion!” profesor Kostić prevodi kao „Avetinjo, stani!” (1986). Duh postepeno nestaje, ne samo sa scene nego i iz govora. Hamlet pominje svoj ,životinjski zaborav", "bestial oblivion” (4.4.9.30), a u 5.2.65 kaže „moj kralj”, ne „moj otac”. Sećanje na pokojnika je obezličeno. Čak ga ni na kraju drame niko ne pominje. Kada ubije Klaudija, Hamlet kaže „idi za mojom majkom” (5.2.269) - stari Hamlet je zaboravljen. Ali, kada Hamlet kaže „mrtav sam” (5.2.275, 280) i „Umirem, ne mogu živeti” (5.2.294), on govori kao Duh. Nestavši sa scene, Duh se pretvorio u traumatično sećanje kraljevića (GREENBLATT 2001: 228).

Iako mnogi kritičari njene pesme tumače kao priznanje fizičke strane odnosa sa Hamletom, Hugo Klajn (1991: 306) veruje da Ofelija peva o prirodnoj, potisnutoj i nerealizovanoj fantaziji i strahovima: pekareva kći pretvorila se u sovu jer je zakinula Isusa Hrista za malo brašna kada mu je pekla hleb - to je sećanje na ono što je uskratila Hamletu. 
Magbeta progoni sećanje na susret sa vešticama, iako uverava Banka da ne misli na njihove reči. Predskazanje da će postati kralj, ali kralj ,jalovog žezla”, a Banko predak budućih kraljeva, posebno ga uznemirava. Čini se da i Ledi Magbet ima „proročku dušu” kao Hamlet, da je znala (ili barem sanjala) sve o Magbetovom „unapređenju” i pre nego što je primila pismo. Dok je Magbet potrošio sve svoje strahove pre prvog zločina, oguglavši do te mere da je gotovo zaboravio kakav je osećaj strah, Ledi Magbet na početku deluje neustrašivo, ali postepeno je izdaje snaga i skončava ophrvana krivicom i strašnim sećanjima. Magbet se nije usudio da se vrati u prostoriju pokolja zbog traumatične slike kraljevog tela punog krvi i jauka ubijenih slugu, čije kletve su mu se pričinjavale u besanoj noći; Ledi Magbet se pravdala da ne može lično da ubije kralja jer veoma liči na njenog oca. Ona često podseća muža na dato obećanje, apelujući na njegovu muškost. Sećanje na taj čin je traumatično, ali „ono što je urađeno ne može se poništiti”. Uskoro će Magbet poželeti da „poništi” kraljevo ubistvo, kao što će tražiti od lekara da „detraumatizuje” njegovu ženu kako bi je izlečio. Magbet se najviše plaši Banka, zbog čega je i traumatizovan od njegovog duha, iako su veštice ukazale na Magdafa kao jedinog čoveka koga treba da se boji. Ubijanjem svedoka, on ubija i njihova sećanja, dok se svaka žrtva urezuje u sećanje Ledi Magbet. Kao da je, poprimanjem muških osobina koje je želela umesto „mleka ljudske dobrote”, preuzela na sebe muževljeve grehe, čak i one za koje nije ni znala. Poput levka kroz koji su istekli svi njegovi strahovi, ona ih evocira u svom mesečarenju sa ritualnim pranjem ruku od krvi nedužnih, ponavljanjem svojih i Magbetovih reči iz noći kraljeubistva, sećanjem na Magdafovu ubijenu porodicu.

Još je 1594. godine, u delu Užasi noći (Terrors of the Night), Tomas Neš (Thomas Nashe) napisao da noću proživljavamo sav užas onoga što pretrpimo tokom dana. Objasnio je da stvaramo slike o prošlosti i da višak tečnosti noću dovodi do pojava tih slika poput marioneta. „Nije to kajanje, to je strah” (NASHE 2015). Kada čuje krike dvorkinja, Magbet se priseti svojih nekadašnjih strahova, iz vremena dok je još bio u stanju da oseća (V, v, 9-15). 
Britanska profesorka Lori Megvajer rekla je da je sve što zna naučila od Šekspira i da ga je doživela kao „gurua samopomoći”, pronalazeći objašnjenja i mudrosti za gotovo svaku situaciju i međuljudski odnos za sebe i svoje bližnje (2006). Sadašnji nastavnici Katedre za anglistiku imali su privilegiju, čast i blagoslov da gotovo sve što znaju o književnosti nauče od svojih profesora kojima posvećuju ovaj Zbornik. Ako je Šekspir bio „duša svog vremena” ("soul of the age”), kako ga je nazvao Ben Džonson u pesmi koju mu je posvetio nakon smrti (BaTe 2009), naši profesori bili su takođe "not for an age, but for all times", a sećanja na njih nisu samo uspomene sa predavanja, mentorstava i epifanijskih razgovora, nego i njihova dela kapitalne vrednosti, koja će za sticanje znanja, pripremanje ispita ili, prosto, kao „hranu za ljubav” prema lepom i plemenitom koristiti mnoge generacije koje nisu imale sreću da ih sretnu. Iznova će ih oživljavati i učitavati u njih nešto svoje, pretvarajući ih iz dugovečnih u večne, kao što je Šekspir predvideo svoje trajanje kroz bezbroj epoha i kultura u drami Julije Cezar:

How many ages hence

Shall this our lofty scene be acted over

In states unborn and accents yet unknown! (III.i.118-120)

Ili, kako je rekao Anžej Zurovski, „Šekspirova zagonetka je zagonetka našeg vremena. Šekspir uvek traži da mu iznova podarimo život. On nije naš savremenik, ali čeka da ga mi osavremenimo, kao što je i u prošlosti uvek čekao." (ELsom 1989: 171)

\section{IZVORI I CITIRANA LITERATURA}

Barker, Francis, Hulme, Iversen, Loxley. Literature, Politics and Theory. New York: Routledge, 1986.

BARKER, Deborah and Ivo KAMPS (eds.). Shakespeare and Gender: A History. London: Verso 1995.

5 "If music be the food of love, play on" - rekao je vojvoda Orsino na samom početku komedije Bogojavljenska noć (Twelfth Night, I.1.1.). 
Bate, Jonathan. Soul of the Age: the Life, Mond and World of William Shakespeare. London: Penguin, 2009.

Brooker, Peter and Widdowson, Peter (eds.). A Practical Reader in Contemporary Literary Theory. New York: Routledge, 2013.

Dusinberre, Juliet. Shakespeare and the Nature of Women. London: Palgrave Macmillan, 2003.

Elsom, John (ed). Is Shakespeare Still Our Contemporary? London: Routlege, 1989.

Fernie, Ewan and Simon PALFREY. Macbeth, Macbeth (Beyond Criticism). London: Bloomsbury, 2016.

Garber, Marjorie. Shakespeare and Modern Culture. New York: Anchor Books, 2008.

Hawkes, Terence. Meaning by Shakespeare.Routledge, London, 1992.

HAZLiTT, William (ed.). Essays of Michel de Montaigne (translated by Charles Cotton, 1877), www.gutenberg.org

Hоцввоок, Peter (ed.) The Shakespeare International Yearbook, Special Section 6: Shakespeare and Montaigne Revisited, Ashgate, 2006.

Joughin, John (ed.): Philosophical Shakespeare. London, Routledge, 2003.

Jovanov, Svetislav. „Hamlet, origano i otrov za miševe” (dramaturška beleška), u: SCENA. Novi Sad: Sterijino pozorje, 2003.

Jump, John. Shakespeare's Hamlet: Selection of Critical Essays. London: Macmillan, 1968.

KLAJN, Hugo. Frojd,psihoanaliza i literatura. Novi Sad, Matica srpska, 1991. Kostić, Veselin: „Proširenje i suženje značenja pri prevođenju Šekspira”, Mostovi, godina XVIII, jul-septembar, sveska 3, br. 71, Beograd, 1986.

Kотт, Jan. Shakespeare Our Contemporary. New York: Anchor Books, 1966.

Kuić, Ranka. Antologija engleske romantičarske poezije. Beograd: Naučna knjiga, 1986.

Logan, Marie Rose and Rudnytsky, Peter L. (eds.). Contending Kingdoms. Detroit: Wayne State University Press, 1991.

Maguire, Laurie. Where There's a Will There's a Way: Or, All I Really Need to Know I Learned from Shakespeare. New York: Penguin, 2006.

Milanović, Vujadin. Vladika Nikolaj o Šekspiru. Beograd: Srpska Evropa, 1995.

Nashe, Thomas. The Terrors of the Night, Or, A Discourse of Apparitions. London: Penguin Classics, 2015.

Osson, Donald. The Stars of Hamlet. Cambridge: Sky Publishing Corporation, 1998. SAvić, Milisav (ed.). Najlepši eseji Vladete Jerotića. Belgrade: Prosveta, 2002. 
ShaKeSPeARe, William. Complete Works, Stanley Wells and Gary Taylor (eds.). Oxford: Oxford University Press, 1997.

Simon, Bennett. "Hamlet and Trauma Doctors: an Essay at Interpretation", American Imago, Vol.58. Baltimore: The Johns Hopkins University Press, 2001.

Šofranac, Nataša. "Traumatizing Memories and Memorizing Trauma - Hamlet and The Magbeth". Facta Universitatis, vol. 9, No 1, 2011, 47-52.

Strachey, James. The Standard Edition of Complete Psychological Works of Sigmund Freud, Volume XII (1911-1913). London: Hogarth Press and the Institute of Psycho-Analysis, 1964.

TAYlor, Michael (ed). Shakespeare Criticism in the Twentieth Century. Oxford: Oxford University Press, 2001.

Wayne, Valerie. The Matter of Difference: Materialist Feminist Criticism of Shakespeare. Ithaca, New York: Cornell University Press, 1991.

Wells, Stanley and Paul Edmondson. Shakespeare Bites Back. http://bloggingshakespeare.com/wp-content/uploads/2011/10/Shakespeare Bites_Back_Book.pdf 19 December 2011.

Nataša Šofranac

MEMORY OF SHAKESPEARE AND MEMORY IN SHAKESPEARE

Summary

"Is Shakespeare still our contemporary?", asked Shakespearean scholars celebrating the 25th anniversary of Jan Kott's famous book. Kott believed that Shakespeare is always our contemporary, but there are times when he is "more our contemporary than at others" (Kott 1966: 11-12). Bertolt Brecht, whom Kott often quotes, insists that Shakespeare is not timeless but a man of his time and that his 'universality' is in depicting one stage of human development (Kott 1966: 4).

Rome is a good example of what Richard Burt calls discursive determinism - how the history of Rome applies to Renaissance and how we read Julius Caesar interpreting it through the present. Shakespeare has been interpreted in Lacanian, Foucaldian, Derridean feminist, Marxist, psychoanalytic, new historicist and deconstructive vocabularies. But Shakespeare also contributes to other disciplines, providing case studies for psychiatry and psychoanalysis. Hamlet or Macbeth and PTSD - where traumatic events are not entirely in the past - offer stories that 
cannot be told directly in narrative discourse, thus finding expression through displacement, symbolisation and action, as Freud spelled out in "Remembering, Repeating and Working Through", in 1914. The memories may not be possible to put into words at all, but expressed non-verbally, encoded as bodily experiences and knowledge becomes confused and disavowed in traumatic states.

Keywords: Shakespeare, memory, interpretation, Hamlet, Macbeth.

Univerzitet u Beogradu

Filološki fakultet

natashapixie@yahoo.co.uk 